\title{
Effectiveness of TI-RADS and ATA classifications for predicting malignancy of thyroid nodules
}

\author{
Murat Şahin ${ }^{1, A-F}$, Ayten Oguz ${ }^{2, A, C, E, F}$, Dilek Tuzun ${ }^{1, A, B, D-F}$, Gülsüm Akkus s, $3, \mathrm{~A}, \mathrm{~B}, \mathrm{E}, \mathrm{F}$, \\ Gul Inci Törün ${ }^{4, A, B, E, F}$, Abdulkadir Yasir Bahar ${ }^{5, A, C, F}$, Hatice Şahin ${ }^{6, A, B, E, F}$, Kamile Gül ${ }^{2, A, C, E, F}$ \\ ${ }^{1}$ Department of Endocrinology and Metabolism, Kahramanmaraş Sütçü Imam University, Turkey \\ ${ }^{2}$ Department of Endocrinology and Metabolism, Gaziantep Liv Hospital, Turkey \\ ${ }^{3}$ Department of Internal Medicine, Etimesgut Şehit Sait Ertürk State Hospital, Ankara, Turkey \\ ${ }^{4}$ Department of Internal Medicine, Afsin State Hospital, Kahramanmaraş, Turkey \\ ${ }^{5}$ Department of Pathology, Faculty of Medicine, Kahramanmaraş Sütçü Imam University, Turkey \\ ${ }^{6}$ Department of Pulmonology, Kahramanmraş Necip Fazıl State Hospital, Turkey \\ A - research concept and design; B - collection and/or assembly of data; $\mathrm{C}$ - data analysis and interpretation; \\ $D$ - writing the article; $E$ - critical revision of the article; $F$ - final approval of the article
}

\section{Address for correspondence \\ Murat Şahin}

E-mail:muratsahin@me.com

Funding sources

None declared

Conflict of interest

None declared

Received on May 4, 2021

Reviewed on June 27, 2021

Accepted on June 29, 2021

Published online on September 9, 2021

Cite as

Sahin M, Oguz A, Tuzun D, et al. Effectiveness of TI-RADS and ATA classifications for predicting malignancy of thyroid nodules. Adv Clin Exp Med. 2021;30(11):1133-1139. doi:10.17219/acem/139591

DOI

10.17219/acem/139591

Copyright

Copyright by Author(s)

This is an article distributed under the terms of the

Creative Commons Attribution 3.0 Unported (CC BY 3.0)

(https://creativecommons.org/licenses/by/3.0/)

\section{Abstract}

Background. Thyroid cancer is one of the most common cancers and is especially common in young patients. Therefore, effective recognition and treatment of thyroid cancer are essential for patient survival.

Objectives. To compare the effectiveness of standard guidelines for predicting thyroid malignancy. To do so, thyroid nodules were classified according to the categories of the American Thyroid Association (ATA) and Thyroid Imaging Reporting and Data System (TI-RADS) guidelines, and compared with fine-needle aspiration biopsy (FNAB) results.

Materials and methods. The study included 1741 thyroid nodules with a final diagnosis in 1121 consecutive patients. The FNAB was recommended for all patients according to ATA guidelines and subsequently performed. The nodules were reclassified according to TI-RADS guidelines.

Results. Comparing nodules classified according to ATA and TI-RADS in terms of ultrasonography (US) features with the Bethesda cytological diagnosis classification System for Reporting Thyroid Cytopathology, $37.6 \%$ of the nodules classified in the high-risk category according to the ATA classification were found to be malignant cytology, $10.4 \%$ suspicious for malignancy, $4 \%$ non-diagnostic, $9.6 \%$ indeterminant cytology, and $38.4 \%$ benign. According to the TI-RADS risk category, 50\% of those with high suspicion were malignant, 13.3\% suspicious for malignancy cytology and 36.7\% were benign. For the TI-RADS guidelines, the best cutoff value for differentiating benign and malignant nodules was found to be 4.5 (area under the curve $(A \cup C)=0.962,95 \%(\mathrm{Cl}=0.943-0.981, \mathrm{p}<0.001)$. For the ATA guidelines, the best cutoff value for separating benign and malignant nodules was 4.5 ( $\mathrm{AUC}=0.917,95 \% \mathrm{Cl}=0.875-0.959, \mathrm{p}<0.001)$. The diagnostic performances of the TI-RADS and ATA score systems were evaluated using highly suspicious nodules. The sensitivity and specificity of highly suspicious nodules, according to both TI-RADS and ATA guidelines, were both high. Sensitivity and specificity of ATA classification were $80 \%$ and $96.3 \%$, respectively. Sensitivity and specificity of TI-RADS classification were $76 \%$ and $97.5 \%$, respectively, but positive predictive value was low (63.3\% compared to 55.5\%).

Conclusions. Both, the ATA and TI-RADS classifications can effectively predict malignancy risk of thyroid nodules and may thus decrease unnecessary FNAB.

Key words: thyroid nodule, ultrasonography, risk of malignancy, fine-needle aspiration 


\section{Background}

The frequency of thyroid nodules detection has increased in recent years, largely due to the widespread use of ultrasonography (US) in more places. While the prevalence of thyroid nodules is detected at a rate of $4 \%$ with palpation, its prevalence varies between 190 and 347 per 1000 cases when thyroid US is used; in autopsy series where nodules are most clearly evaluated, the prevalence is between 82 and 650 in 1000 autopsies. ${ }^{1}$ Thyroid nodules warrant medical attention because of the possibility of cancer development. The incidence of thyroid cancer is increasing all over the world. ${ }^{2}$ According to 2020 cancer statistics for the USA, thyroid cancer is most commonly reported in people aged 15-39. Among all cancers that develop between the age of 30 and 39, thyroid cancer is the most common type of cancer in men and the $2^{\text {nd }}$ most common in women. ${ }^{2}$

Because thyroid cancer is one of the most common cancers and occurs in young patients, effective recognition and treatment are very important for the survival of patients. Some evidence-based guidelines have been developed for the evaluation of patients presenting with thyroid nodules. The American Thyroid Association (ATA) recommends thyroid US along with cervical lymph node examination in patients with suspected thyroid nodules. ${ }^{3}$ Similarly, the National Comprehensive Cancer Network (NCCN) recommends evaluating the lateral neck compartment lymph nodes along with thyroid US in all patients with an incidentally detected neck mass. ${ }^{4}$ When performing thyroid US, the clinical aim is to detect nodules with a high-risk of thyroid cancer. The presence of findings such as microcalcifications, irregular margins and marked hypoechogenicity indicates a higher risk of malignancy. Existing guidelines classify thyroid nodules into risk categories according to the abovementioned suspicious features and make recommendations for biopsy. In the ATA guidelines, fine-needle aspiration biopsy (FNAB) is recommended at $1 \mathrm{~cm}$ and above for high- or moderatesuspicion nodules, $1.5 \mathrm{~cm}$ and above for low-suspicion nodules and $2 \mathrm{~cm}$ and above for very-low-suspicion nodules. ${ }^{3}$ In the Thyroid Imaging Reporting and Data System (TI-RADS) developed by the American College of Radiology (ACR), FNAB is recommended at $1 \mathrm{~cm}$ and above for nodules in the high-suspicion category, $1.5 \mathrm{~cm}$ and above in the moderate-suspicion category and $2.5 \mathrm{~cm}$ and above in the mild-suspicion category. ${ }^{5}$

\section{Objectives}

The efficacy of FNAB recommendations based on the ATA and TI-RADS guidelines in predicting malignancy of thyroid nodules has been reported in previous studies. Both ATA and TI-RADS guidelines classify nodules into risk groups. Although there are some similarities, the classifications also differ in some aspects. Currently, it is not clear whether these differences in the classifications may result in differences in predicting malignancy. In the present study, we aimed to classify biopsied thyroid nodules according to the risk categories of both guidelines and then evaluate whether there is a difference between the guidelines in predicting malignancy.

\section{Materials and methods}

The Ethics Committee of Kahramanmaraş Sütçü İmam University (KSU), Kahramanmaraş, Turkey, approved this retrospective, cross-sectional study (approval No. 22, decision date March 6, 2019).

\section{Subjects}

This study included a total of 1741 thyroid nodules (this number was determined using power analysis), with final diagnosis in 1121 consecutive patients (age: $51.54 \pm 13.53$ years). Routine US-guided FNAB (USg-FNAB) was performed according to the 2015 ATA guidelines. ${ }^{3}$

\section{US examination and image analysis}

Ultrasound machines (General Electric Logic P5; General Electric, Schenectady, USA) equipped with a 12$\mathrm{MHz}$ linear probe were used for analysis. Generally, USgFNAB is recommended for all patients with hypoechoic solid nodules $\geq 1 \mathrm{~cm}$ in diameter, isoechoic solid nodules $\geq 1.5 \mathrm{~cm}$, mixed cystic-solid nodules and spongiform nodules $\geq 2 \mathrm{~cm}$, and high-risk history with nodules $\geq 5 \mathrm{~mm}$ according to the ATA guidelines. Microcalcification, tallerthan-wide shape, irregular margins, and pronounced hypoechogenicity are considered suspicious characteristics. Biopsy was not performed because pure cystic nodules are considered benign.

The nodules were then reclassified in accordance with the ACR TI-RADS guidelines and evaluated in terms of echogenic foci, margin irregularity, taller-than-wide shape, and calcification and microcalcification. The risk category of the nodules was scored according to these features. Nodules were classified as benign (TR1, 0 points), very low suspicion (TR2, 2 points), low suspicion (TR3, 3 points), intermediate suspicion (TR4, 4-6 points), and high suspicion (TR5, $\geq 7$ points). ${ }^{5}$

\section{FNAB}

The FNAB was performed by endocrinologists under US guidance using 23-27 gauge needles. The FNAB procedure was performed with the patient lying in the supine position, with the neck extended. During the procedure, a sample was taken from all sides of the nodule. Biopsy was taken from solid parts in mixed echogenic nodules. 


\section{Cytopathological analysis}

Cytopathological interpretation of FNAB samples was performed using the Bethesda System for Reporting Thyroid Cytopathology. ${ }^{6}$ Retrospective reclassification of all nodules according to TI-RADS system was blind regarding the FNAB results. ${ }^{5}$

\section{Statistical analyses}

Statistical analyses were performed using IBM SPSS v. 22.0 for Windows (IBM Corp., Armonk, USA). Continuous data are presented as mean \pm standard deviation (SD). Categorical variables were evaluated using the McNemar's and Pearson's $\chi^{2}$ test. Nominal data are given as number of cases and percentage. The independent two-sample t-test was used to compare 2 groups in terms of age and thyroid stimulating hormone (TSH) level. We measured the specificity, sensitivity, negative/positive predictive value (PPV), and accuracy of both guidelines in terms of the diagnosis of malignant thyroid nodules. The malignancy risk of the TI-RADS scores and groups and the ATA risk stratification grades were measured on the basis of the cytopathological findings. The diagnostic performance of the TI-RADS and ATA score systems were evaluated using receiver operating curve (ROC) analysis based on high-suspicion nodules. Differences were considered to be statistically significant when $\mathrm{p}<0.05$.

\section{Results}

\section{Demographic and laboratory findings}

The malignancy rate was $5.0 \%(\mathrm{n}=36)$ in women and $4.9 \%(n=8)$ in men, and the difference was not statistically significant $(\mathrm{p}=0.512)$. The mean age of patients with benign cytology results was $51.68 \pm 13.39$ years and for malignant cases mean age was $50.84 \pm 16.15$ years; the difference was not statistically significant $(p=0.517)$. Additionally, when patients with malignant and benign cytology results were compared in terms of TSH levels $(1.88 \pm 0.44$ compared to $65 \pm 0.52 \mathrm{mIU} / \mathrm{L}$, respectively), no significant difference was found $(\mathrm{p}=0.526)$.

\section{Thyroid US and USg-FNAB cytological findings}

The US findings for the thyroid nodules are shown in Table 1. Ultrasonography-guided FNAB and cytological

Table 1. Ultrasonography findings and cytologic results of thyroid nodules for which fine-needle aspiration biopsy (FNAB) was performed

\begin{tabular}{|c|c|c|c|c|c|c|c|}
\hline \multirow{2}{*}{$\begin{array}{l}\text { Ultrasonography } \\
\text { findings }\end{array}$} & \multirow{2}{*}{$\begin{array}{l}\text { Total } \\
\mathrm{n}(\%)\end{array}$} & \multicolumn{2}{|c|}{ Cytological diagnosis } & \multicolumn{3}{|c|}{ Cytological diagnosis } & \multirow[b]{2}{*}{$p$-value } \\
\hline & & $\begin{array}{c}\text { non- } \\
\text { diagnostic }\end{array}$ & benign & indeterminate & suspicious & malignant & \\
\hline Total (nodule) & 1741 & $148(8.5)$ & $1327(76.2)$ & $191(11.0)$ & $23(1.3)$ & $52(3.0)$ & - \\
\hline Total (patient) & 1121 & $84(7.5)$ & $842(75.2)$ & $153(13.6)$ & $16(1.4)$ & $26(2.3)$ & - \\
\hline $\begin{array}{l}\text { Sex } \\
\text { female } \\
\text { male }\end{array}$ & $\begin{array}{l}913(81.4) \\
208(18.6)\end{array}$ & $\begin{array}{l}63(6.9) \\
20(9.6)\end{array}$ & $\begin{array}{l}689(75.5) \\
154(74.0)\end{array}$ & $\begin{array}{l}113(12.4) \\
23(11.1)\end{array}$ & $\begin{array}{c}12(1.3) \\
3(1.4)\end{array}$ & $\begin{array}{c}36(3.9) \\
8(3.8)\end{array}$ & 0.006 \\
\hline $\begin{array}{l}\text { Size } \\
\text { subcentimeter } \\
\text { supracentimeter }\end{array}$ & $\begin{array}{c}69(4.0) \\
1672(96.0)\end{array}$ & $\begin{array}{c}7(10.1) \\
141(8.4)\end{array}$ & $\begin{array}{c}38(55.1) \\
1289(77.1)\end{array}$ & $\begin{array}{c}13(18.8) \\
178(10.6)\end{array}$ & $\begin{array}{c}3(4.3) \\
20(1.2)\end{array}$ & $\begin{array}{l}8(11.6) \\
44(2.6)\end{array}$ & 0.000 \\
\hline $\begin{array}{l}\text { Echogenicity } \\
\text { anechoic } \\
\text { isoechoic/hyperechoic } \\
\text { hypoechoic } \\
\text { marked hypoechoic }\end{array}$ & $\begin{array}{c}6(0.4) \\
1289(74.0) \\
444(25.5) \\
2(0.1)\end{array}$ & $\begin{array}{c}3(50.0) \\
99(7.7) \\
46(10.4) \\
0(0.0)\end{array}$ & $\begin{array}{c}1(16.7) \\
1027(79.7) \\
299(67.3) \\
0(0.0)\end{array}$ & $\begin{array}{c}2(33.3) \\
125(9.7) \\
64(14.4) \\
0(0.0)\end{array}$ & $\begin{array}{c}0(0.0) \\
11(0.9) \\
12(2.7) \\
0(0.0)\end{array}$ & $\begin{array}{c}0(0.0) \\
27(2.1) \\
23(5.2) \\
2(100.0)\end{array}$ & 0.000 \\
\hline $\begin{array}{l}\text { Calcification } \\
\text { absent } \\
\text { macrocalcification } \\
\text { peripheral calcification } \\
\text { microcalcification }\end{array}$ & $\begin{array}{c}1428(82.1) \\
293(16.8) \\
4(0.2) \\
16(0.9)\end{array}$ & $\begin{array}{l}119(8.3) \\
29(9.9) \\
0(0.0) \\
0(0.0)\end{array}$ & $\begin{array}{c}1107(77.5) \\
217(74.1) \\
3(75.0) \\
0(0.0)\end{array}$ & $\begin{array}{c}155(10.9) \\
35(11.9) \\
0(0.0) \\
1(6.3)\end{array}$ & $\begin{array}{l}16(1.1) \\
4(1.4) \\
0(0.0) \\
3(18.8)\end{array}$ & $\begin{array}{l}31(2.2) \\
8(2.7) \\
1(25.0) \\
12(75)\end{array}$ & 0.000 \\
\hline $\begin{array}{l}\text { Margins } \\
\text { regular } \\
\text { irregular }\end{array}$ & $\begin{array}{c}1612(92.6) \\
129(7.4)\end{array}$ & $\begin{array}{l}133(8.3) \\
15(11.6)\end{array}$ & $\begin{array}{c}1297(80.5) \\
30(23.3)\end{array}$ & $\begin{array}{l}156(9.7) \\
35(27.1)\end{array}$ & $\begin{array}{c}8(0.5) \\
15(11.6)\end{array}$ & $\begin{array}{c}18(1.1) \\
34(26.4)\end{array}$ & 0.000 \\
\hline $\begin{array}{l}\text { Composition } \\
\text { spongiform } \\
\text { mixed } \\
\text { solid }\end{array}$ & $\begin{array}{c}9(0.5) \\
977(56.1) \\
755(43.4)\end{array}$ & $\begin{array}{l}3(33.3) \\
80(8.2) \\
65(8.6)\end{array}$ & $\begin{array}{c}6(66.7) \\
788(80.7) \\
533(70.6)\end{array}$ & $\begin{array}{c}0(0.0) \\
85(8.7) \\
106(14.0)\end{array}$ & $\begin{array}{c}0(0.0) \\
9(0.9) \\
14(1.9)\end{array}$ & $\begin{array}{c}0(0.0) \\
15(1.5) \\
37(4.9)\end{array}$ & 0.000 \\
\hline $\begin{array}{l}\text { Shape } \\
\text { ovoid } \\
\text { spheric }\end{array}$ & $\begin{array}{c}1694(97.3) \\
47(2.7)\end{array}$ & $\begin{array}{c}148(8.7) \\
0(0)\end{array}$ & $\begin{array}{c}1320(77.9) \\
7(14.9)\end{array}$ & $\begin{array}{l}174(10.3) \\
17(36.2)\end{array}$ & $\begin{array}{l}17(1.0) \\
6(12.8)\end{array}$ & $\begin{array}{c}35(2.1) \\
17(36.2)\end{array}$ & 0.000 \\
\hline
\end{tabular}




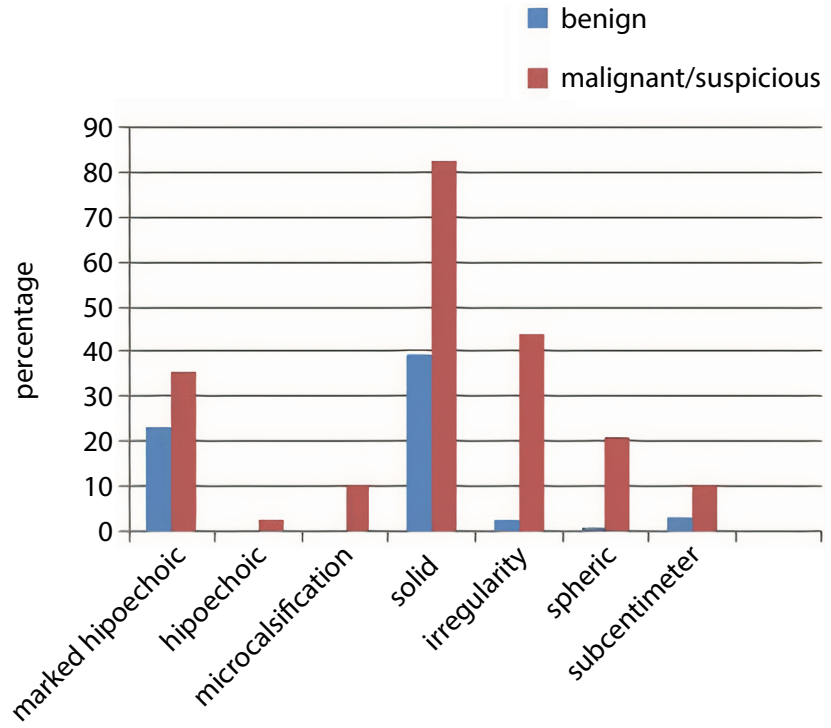

Fig. 1. Percentage distribution of ultrasonography features of nodules with malignant/suspicious or benign cytology

analysis were performed on 1741 nodules of 1121 cases. When non-diagnostic cytology findings were detected after the first USg-FNAB, repeat FNAB was performed. Accordingly, we determined that 1327 out of 1741 nodules were benign (76.2\%), 148 were non-diagnostic (8.5\%), 191 were indeterminate (in Bethesda classification, indeterminate cytology includes FLUS (follicular lesion of undetermined significance) and AUS (atypia of undetermined significance)) and/or follicular/Hurthle cell neoplasm (11.0\%), 23 were suspicious (1.3\%), and 52 (3.0\%) were malignant cytological findings.

Figure 1 shows the percentage distribution of US features of nodules with malignant/suspicious and benign cytology findings. When malignant/suspicious and benign nodules were compared, hypoechogenicity (36\% compared to $23.2 \%$ ), marked hypoechogenicity $(2.7 \%$ compared to $0.0 \%)$, microcalcification ( $10.7 \%$ compared to $0.0 \%)$, solid composition (82.7\% compared to $39.8 \%)$, taller-than-wide shape (21.3\% compared to $1.1 \%)$, and margin irregularity (44.0\% compared to $3.0 \%$ ) were significantly more common in malignant/suspicious nodules $(\mathrm{p}<0.001)$. Separate tests were performed for each feature and all values were $<0.0001$. The p-values of each test were shown in Table 1.

\section{Diagnostic performance of ATA and TI-RADS}

When we compared the nodules classified according to ATA and TI-RADS in terms of ultrasonography (US) features with the Bethesda cytological diagnosis classification System for Reporting Thyroid Cytopathology, 37.6\% of the nodules classified in the high-risk category according to the ATA classification were found to be malignant cytology, $10.4 \%$ suspicious for malignancy, $4 \%$ non-diagnostic, $9.6 \%$ indeterminant cytology, and $38.4 \%$ benign. According to the TI-RADS risk category, $50 \%$ of those with high suspicion were malignant, $13.3 \%$ were suspicious for malignancy cytology and $36.7 \%$ were benign. Of note, $12.9 \%$ and $0.5 \%$ (226 of 1741 and 10 of 1741) of the nodules did not fit any category in the ATA and TI-RADS guidelines, respectively. There was no malignancy in any of these nodules (Table 2).

As suggested by the ROC curve analysis (Fig. 2), for the TI-RADS classification, the best cutoff value in differentiating benign and malignant nodules was found to be 4.5. Accordingly, a nodule with TR5 is likely malignant, and a nodule with TR4 or below is likely benign. The most reliable diagnosis based on TI-RADS was obtained using

Table 2. Cytological diagnosis rate according to the American Thyroid Association (ATA) and Thyroid Imaging Reporting and Data System (TI-RADS) risk categories

\begin{tabular}{|c|c|c|c|c|c|c|}
\hline \multirow[b]{2}{*}{ Ultrasonography findings } & \multirow{2}{*}{$\begin{array}{c}\text { Total } \\
n\end{array}$} & \multicolumn{5}{|c|}{ Cytological diagnosis } \\
\hline & & $\begin{array}{c}\text { non-diagnostic } \\
n(\%)\end{array}$ & $\begin{array}{l}\text { benign } \\
n(\%)\end{array}$ & $\begin{array}{c}\text { indeterminate } \\
n(\%)\end{array}$ & $\begin{array}{c}\text { suspicious } \\
\text { n (\%) }\end{array}$ & $\begin{array}{c}\text { malignant } \\
\mathrm{n}(\%)\end{array}$ \\
\hline Out of category & 226 & $35(15.4)$ & $168(74.3)$ & $23(10.2)$ & $0(0)$ & $0(0)$ \\
\hline Benign & 9 & $0(0)$ & $9(90.0)$ & $0(0)$ & $0(0)$ & $0(0)$ \\
\hline Low suspicion & 1269 & $106(8.4)$ & $1001(78.9)$ & $153(12.1)$ & $9(0.7)$ & $0(0)$ \\
\hline Intermediate suspicion & 29 & $0(0.0)$ & $21(72.4)$ & $3(10.3)$ & $0(0)$ & $5(17.2)$ \\
\hline High suspicion & 125 & $5(4.0)$ & $48(38.4)$ & $12(9.6)$ & $13(10.4)$ & $47(37.6)$ \\
\hline \multicolumn{7}{|c|}{ TI-RADS category } \\
\hline Out of category & 10 & $4(40.0)$ & $5(50.0)$ & $1(10.0)$ & $0(0)$ & $0(0)$ \\
\hline Not suspicious & 668 & $41(6.1)$ & $531(79.5)$ & $96(14.4)$ & $0(0.0)$ & $0(0)$ \\
\hline Slightly suspicious & 672 & $54(8.0)$ & $520(77.4)$ & $91(13.5)$ & $5(0.7)$ & $2(0.3)$ \\
\hline Intermediately suspicious & 85 & $0(0)$ & $71(83.5)$ & $3(3.5)$ & $6(7.1)$ & $5(5.9)$ \\
\hline Highly suspicious & 90 & $0(0)$ & $33(36.7)$ & $0(0)$ & $12(13.3)$ & $45(50.0)$ \\
\hline
\end{tabular}




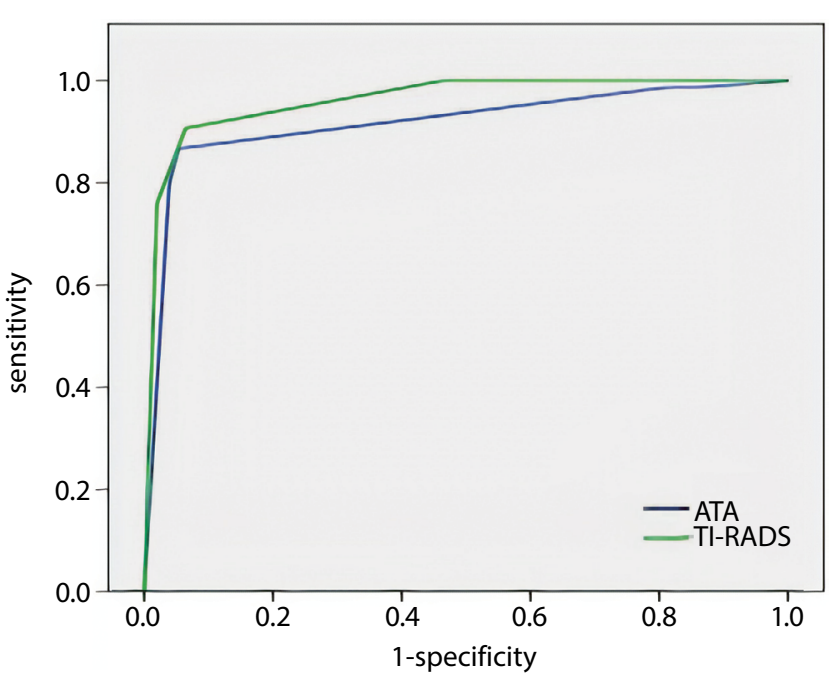

Fig. 2. The receiver operating curve (ROC) of the American College of Radiology (ACR) and American Thyroid Association (ATA) guidelines (TI-RADS - Thyroid Imaging Reporting and Data System)

Table 3. Diagnostic value of the ATA and TI-RADS risk classifications for the detection of malignant/suspicious thyroid nodules

\begin{tabular}{|l|c|c|}
\multicolumn{1}{|c|}{ Parameter } & ATA-high suspicion & $\begin{array}{c}\text { TI-RADS-high } \\
\text { suspicion }\end{array}$ \\
\hline Sensitivity & $60 / 75(80.0 \%)$ & $57 / 75(76.0 \%)$ \\
\hline Specificity & $1279 / 1327(96.3 \%)$ & $1294 / 1327(97.5 \%)$ \\
\hline PPV & $60 / 108(55.5 \%)$ & $57 / 90(63.3 \%)$ \\
\hline NPV & $1279 / 1294(98.8 \%)$ & $1294 / 1312(98.6 \%)$ \\
\hline Accuracy & $1339 / 1402(95.5 \%)$ & $1351 / 1402(96.3 \%)$ \\
\hline
\end{tabular}

Sensitivity - number of true positives divided by the number of true positives plus the number of false negatives; specificity - number of true negatives divided by the number of true negatives plus the number of false positives; positive predictive value (PPV) - number of true positives divided by the number of true positives plus the number of false positives; negative predictive value (NPV) - number of true negatives divided by the number of true negatives plus the number of false negatives; accuracy - number of true positives plus the number of true negatives divided by the number of true positives plus the number of true negatives plus the number of false positives plus the number of false negatives; ATA - American Thyroid Association; TI-RADS - Thyroid Imaging Reporting and Data System.

this cutoff value (area under the curve $(A U C)=0.962,95 \%$ confidence interval $(95 \% \mathrm{CI})=0.943-0.981, \mathrm{p}<0.001)$. Using the ATA guidelines, the best cutoff value for differentiating benign and malignant nodules was 4.5 . This means that if a nodule is in the high-suspicion category, it is likely malignant; if it is in the intermediate or lower-suspicion category, it is likely benign. The most reliable diagnosis based on the ATA guidelines was obtained using this cutoff value $(\mathrm{AUC}=0.917,95 \% \mathrm{CI}=0.875-0.959, \mathrm{p}<0.001$ ).

The diagnostic performances of the TI-RADS and ATA score systems were evaluated based on high-suspicion nodules. The sensitivity and specificity of high-suspicion nodules according to both TI-RADS and ATA were both high (76\% compared to $80 \%$ and $97.5 \%$ compared to $96.3 \%$, respectively), but PPV was low (63.3\% compared to $55.5 \%$; Table 3).

\section{Discussion}

Thyroid cancers are observed more frequently in women. In a large-scale study, approx. $75 \%$ of thyroid cancer cases were reported to be women. ${ }^{7}$ In our study, when the sexes were evaluated separately, the rate of cases with malignancy confirmed using FNAB was found to be similar (4.9\% in men, $5 \%$ in women). However, when all patients who underwent FNAB were evaluated, the majority of patients with malignancy were women. Thus, this finding is consistent with previous findings stating that the incidence of thyroid cancer is higher in women.

In this study, the Bethesda classification was used for pathological evaluation of FNAB performed on the thyroid nodules. The malignancy risk of each category in the Bethesda system has been demonstrated in prior studies: while the risk of malignancy in the benign category is approx. $0-3 \%$, it is $97-99 \%$ in the malignant category, which means that the Bethesda system can accurately estimate the risk of malignancy. ${ }^{6}$ In the Bethesda system, the non-diagnostic category is applied when the sample is not large enough to reach a conclusion. In a previous study, this category was applied to $16 \%$ of first biopsies; when a second biopsy was performed in patients with non-diagnostic results, sufficient samples were taken from most of these patients. ${ }^{8}$ In our study, the rate of the nondiagnostic category was $8.5 \%$. It has been suggested that the category of atypia of undetermined significance (AUS)/ follicular lesion of undetermined significance (FLUS) in the Bethesda system should be below 7\%, if possible, in all thyroid FNAB results, although a value of $10 \%$ is more reasonable. ${ }^{6}$ In our study, the AUS/FLUS category was $11 \%$ of all FNAB results.

The ATA classifies nodules into risk categories and makes FNAB recommendations accordingly. The ATA high-risk category is reported to have an approx. 70-90\% malignancy risk. In a study evaluating the malignancy risk of nodules according to the ATA classification, malignancy was detected in approx. $67.5 \%$ of the nodules considered high-risk ones. ${ }^{9}$ A nother study reported a malignancy risk of approx. 83\% for high-risk nodules classified using ATA guidelines. ${ }^{10}$ In our study, $48 \%$ of the nodules classified as high-risk according to the ATA risk category were found to have malignant/suspicious cytology results.

In the TI-RADS classification, points are given according to the characteristics of the nodules and the risk classification of the nodules is made considering the total score. In a study investigating the malignancy risk of the TIRADS classification, the frequency of malignancy was approx. $20.6 \%$ for nodules in the high-suspicion category, from $5.9 \%$ to $12.8 \%$ for nodules in the moderate-suspicion category, and $4.8 \%$ in the mild-suspicion category. ${ }^{11}$ In another study comparing the FNAB results of nodules classified according to the TI-RADS classification, the frequency of malignancy/suspected malignancy in TR5 nodules was observed at a rate of $60 \%$. When the benign FNAB results 
were examined, it was determined as $100 \%$ in the TR2 category, $66 \%$ in the TR3 category, 33\% in the TR4 category, and $40 \%$ in the TR5 category. ${ }^{12}$ In another study, malignancy was detected histopathologically in $97.1 \%$ of nodules in the TR 5 category and $33.3 \%$ of nodules in the TR3 category. ${ }^{13}$ In our study, similar to the literature, $63.3 \%$ of nodules in the TI-RADS TR 5 category were found to be histopathologically malignant/suspected for malignancy.

Malignancy risk is significantly higher in high-suspicion nodules compared with other nodules in both the ATA and TI-RADS classifications. Gao et al. reported a malignancy rate of $88 \%$ in the TI-RADS TR5 category and the best cutoff value in predicting malignancy according to the ROC curve was TR5. For the ATA risk classification, the risk of malignancy in highly suspicious nodules was found to be $87.3 \%$ and the best cutoff value in predicting malignancy according to the ROC curve was the category of highly suspicious nodules. ${ }^{14}$ In another study comparing the ATA and TI-RADS risk classifications, the rate of malignancy was found to be $65 \%$ in nodules in the ATA high-risk group and $73.6 \%$ in nodules in the TI-RADS TR5 category. The authors also found that TI-RADS TR5 and the ATA high-suspicion nodule category were best at distinguishing between benign and malignant nodules. When the sensitivity and specificity of both diagnostic classifications were evaluated, it was observed that the ATA classification was more sensitive and the TI-RADS classification was more specific. ${ }^{15}$ In a study conducted by Koc et al., 45 nodules were observed as malignant, 34 of which had FNAB indication for TI-RADS, while 38 nodules had FNAB indication according to the ATA classification. In the same study, the sensitivity of TI-RADS was found to be $48.8 \%$ and the specificity was $59.9 \%$, while the sensitivity of the ATA classification was $82.2 \%$ and the specificity was $53.47 \% .{ }^{16}$ A study evaluating the TIRADS classification found $81.4 \%$ malignancy in the TR5 category, $40.1 \%$ in the TR4 category, $7.5 \%$ in the TR3 category, $2.3 \%$ in the TR2 category, and no malignant cytology in the TR1 category. In addition, the study found that the sensitivity of TI-RADS was $96.6 \%$, the specificity was $52.9 \%$ and the cutoff category for predicting malignancy was TR $4 .{ }^{17}$ In a study by Huang et al., when the ATA and TI-RADS classifications were compared, the sensitivity of the ATA classification was $92 \%$ and the specificity was $10 \%$, while the sensitivity of the TI-RADS classification was $74 \%$ and the specificity was $47 \%$. As a result, the ATA classification was found to be more sensitive, while the TI-RADS classification was more specific. ${ }^{18}$ In the present study, when we evaluated the power of both classifications to recognize malignancy, we found that the sensitivity of the ATA risk classification was $80 \%$ and the specificity was $96.3 \%$, while the sensitivity of the TI-RADS classification was $76 \%$ and the specificity was $97.5 \%$. According to these results, ATA and TI-RADS have high specificity and sensitivity. We also found that the best category for distinguishing malignant and benign nodules was TR5 for TI-RADS and the highsuspicion category for ATA.
While almost all nodules are included in a given category in the ATA and TI-RADS classifications, some nodules are outside of a category. In the ACR-TI-RADS classification, the TR1 category includes nodules scoring 0 and the TR 2 category includes nodules scoring 2 points; thus, nodules scoring 1 point do not fall into any category. Similarly, in the ATA classification, some nodules are outside of a category. According to the ATA classification, the high-risk nodule category includes hypoechoic nodules with suspicious features, the moderate-risk category includes hypoechoic nodules without suspicious features, and the low-risk category includes isoechoic nodules without suspicious features. Therefore, isoechoic nodules with suspicious features fall outside of a category. In a prior study, the frequency of nodules that could not be classified according to ATA category was $3.4 \%$ and the frequency of malignancy in these nodules was $18.2 \%{ }^{19}$ In a study by Lauria Pantano et al., 54 of 1077 nodules included in the study did not fit any category in the ATA classification, and 9 of them were cytologically high-risk ones. ${ }^{20}$ In our study, when evaluated according to the ATA category, $12 \%$ of the nodules were found to be outside of a category, and $0.5 \%$ of these nodules were classified as non-categorized according to the TI-RADS classification. However, no malignancy or suspected malignancy cytology result was observed in any of the nodules that were outside of a category in both classifications.

\section{Limitations}

While we compared the risk categories using both guidelines with the FNAB results, we did not compare risk categories with final pathological results after thyroidectomy because we were not able to follow up with sufficient patients.

\section{Conclusions}

Our findings support that both the ATA and TI-RADS classifications can effectively predict malignancy risk in thyroid nodules. Both methods are effective at detecting malignancy in patients and preventing unnecessary FNAB.

\section{ORCID iDs}

Murat Şahin (1) https://orcid.org/0000-0001-7969-9157 Ayten Oguz (D) https://orcid.org/0000-0002-9518-8610 Dilek Tuzun (1) https://orcid.org/0000-0002-6693-4928 Gülsüm Akkus (D) https://orcid.org/0000-0002-3819-8169 Gul Inci Törün (D) https://orcid.org/0000-0002-6106-4935 Abdulkadir Yasir Bahar (D) https://orcid.org/0000-0002-6963-3389 Hatice Şahin (D) https://orcid.org/0000-0002-3317-3640 Kamile Gül (D) https://orcid.org/0000-0002-2145-770X

\section{References}

1. Dean DS, Gharib H. Epidemiology of thyroid nodules. Best Pract Res Clin Endocrinol Metab. 2008;22(6):901-911. doi:10.1016/j.beem.2008. 09.019 
2. American Cancer Society. Cancer Facts \& Figures 2020. Atlanta, USA: American Cancer Society; 2020. https://www.cancer.org/content/ dam/cancer-org/research/cancer-facts-and-statistics/annual-cancerfacts-and-figures/2020/special-section-cancer-in-adolescents-andyoung-adults-2020.pdf.

3. Haugen BR, Alexander EK, Bible KC, et al. 2015 American Thyroid Association Management Guidelines for Adult Patients with Thyroid Nodules and Differentiated Thyroid Cancer: The American Thyroid Association Guidelines Task Force on Thyroid Nodules and Differentiated Thyroid Cancer. Thyroid. 2016;26(1):1-133. doi:10.1089/thy. 2015.0020

4. National Comprehensive Cancer Network. Thyroid cancer (Version 2.2020). https://www.nccn.org/patients/guidelines/content/PDF/ thyroid-patient.pdf. Plymouth Meeting, USA; 2020.

5. Tessler FN, Middleton WD, Grant EG, et al. ACR Thyroid Imaging Reporting and Data System (TI-RADS): White Paper of the ACR TI-RADS Committee. J Am Coll Radiol. 2017;14(5):587-595. doi:10. 1016/j.jacr.2017.01.046

6. Cibas ES, Ali SZ. The 2017 Bethesda System for Reporting Thyroid Cytopathology. Thyroid. 2017;27(11):1341-1346. doi:10.1089/thy.2017.0500

7. Lim H, Devesa SS, Sosa JA, Check D, Kitahara CM. Trends in thyroid cancer incidence and mortality in the United States, 1974-2013. JAMA. 2017;317(13):1338-1348. doi:10.1001/jama.2017.2719

8. Jack GA, Sternberg SB, Aronson MD, Mukamal KJ, Oshin A, Hennessey JV. Nondiagnostic fine-needle aspiration biopsy of thyroid nodules: Outcomes and determinants. Thyroid. 2020;30(7):992-998. doi:10. 1089/thy.2019.0140

9. Chng CL, Tan HC, Too CW, et al. Diagnostic performance of ata, bta and tirads sonographic patterns in the prediction of malignancy in histologically proven thyroid nodules. Singapore Med J. 2018; 59(11):578-583. doi:10.11622/smedj.2018062

10. de Macedo BM, Izquierdo RF, Golbert L, Meyer ELS. Reliability of thyroid imaging reporting and data system (TI-RADS), and ultrasonographic classification of the American Thyroid Association (ATA) in differentiating benign from malignant thyroid nodules. Arch Endocrinol Metab. 2018;62(2):131-138. doi:10.20945/2359-3997000000018

11. Middleton WD, Teefey SA, Reading CC, et al. Multiinstitutional analysis of thyroid nodule risk stratification using the American College of Radiology thyroid imaging reporting and data system. Am J Roentgenol. 2017;208(6):1331-1341. doi:10.2214/AJR.16.17613
12. Singaporewalla RM, Hwee J, Lang TU, Desai V. Clinico-pathological correlation of thyroid nodule ultrasound and cytology using the TIRADS and Bethesda classifications. World J Surg. 2017;41(7):1807-1811. doi:10.1007/s00268-017-3919-5

13. George NA, Suresh S, Jiji V, et al. Correlation of TIRADS and Bethesda scoring systems with final histopathology of thyroid nodules: An institutional experience. Indian J Otolaryngol Head Neck Surg. 2021;2021:1-6. doi:10.1007/s12070-021-02380-8

14. Gao L, Xi X, Jiang Y, et al. Comparison among TIRADS (ACR TI-RADS and KWAK-TI-RADS) and 2015 ATA Guidelines in the diagnostic efficiency of thyroid nodules. Endocrine. 2019;64(1):90-96. doi:10.1007/ s12020-019-01843-x

15. Wu XL, Du JR, Wang $H$, et al. Comparison and preliminary discussion of the reasons for the differences in diagnostic performance and unnecessary FNA biopsies between the ACR TIRADS and 2015 ATA guidelines. Endocrine. 2019;65(1):121-131. doi:10.1007/s12020019-01886-0

16. Koc AM, Adıbelli ZH, Erkul Z, Sahin Y, Dilek I. Comparison of diagnostic accuracy of ACR-TIRADS, American Thyroid Association (ATA), and EU-TIRADS guidelines in detecting thyroid malignancy. Eur J Radiol. 2020;2020:109390. doi:10.1016/j.ejrad.2020.109390

17. $\mathrm{Xu} \mathrm{T,} \mathrm{Wu} \mathrm{Y,} \mathrm{Wu} \mathrm{RX,} \mathrm{et} \mathrm{al.} \mathrm{Validation} \mathrm{and} \mathrm{comparison} \mathrm{of} \mathrm{three} \mathrm{newly-}$ released thyroid imaging reporting and data systems for cancer risk determination. Endocrine. 2019;64(2):299-307. doi:10.1007/s12020018-1817-8

18. Huang BL, Ebner SA, Makkar JS, et al. A multidisciplinary head-tohead comparison of American College of Radiology Thyroid Imaging and Reporting Data System and American Thyroid Association Ultrasound Risk Stratification Systems. Oncologist. 2020;25(5):398-403. doi:10.1634/theoncologist.2019-0362

19. Malhi H, Grant E. Both TIRADS and the ATA guidelines provide effective malignancy risk stratification for thyroid nodules. Clin Thyroidol. 2016;28(8):238-240. doi:10.1089/ct.2016;28.238-240

20. Lauria Pantano A, Maddaloni E, Briganti SI, et al. Differences between ATA, AACE/ACE/AME and ACR TI-RADS ultrasound classifications performance in identifying cytological high-risk thyroid nodules. Eur J Endocrinol. 2018;178(6):595-603. doi:10.1530/EJE-18-0083 